\title{
Light and Electron Microscopy of the Exocrine Pancreas in the Chronically Reserpinized Rat ${ }^{1}$
}

\author{
GILLES GRONDIN, FRANCOIS A. LEBLOND, JEAN MORISSET, AND DENIS LEBEL \\ Centre de Recherche sur les Mécanismes de Sécrétion, Faculty of Science, University of Sherbrooke, \\ Sherbrooke, QC, Canada, JIK $2 R 1$
}

\begin{abstract}
The effects of reserpine injections were studied on the morphology of the pancreas in an experimental model for cystic fibrosis, the chronically reserpinized rat. A detailed examination of the tissue was carried out at the light and electron microscopic levels. The nonspecific effects of secondary malnutrition induced by the drug were assessed with a group of animals pair fed with the treated animals. In a companion paper, we show that pancreatic wt, lipase, and GP-2 contents also are affected by reserpine treatment. In this study, we report that no morphologic differences were observed between the exocrine pancreatic tissue of control and pair-fed animals. By contrast, reserpine induced an accumulation of zymogen granules in $60 \%$ of the treated animals and a concomitant decrease of the area occupied by the rough endoplasmic reticulum in the same cells. Finally, in all treated animals, at the light and electron microscopic levels, it was observed that some particular regions of the pancreatic tissue were strongly affected. In these regions, numerous autophagic bodies and lysosomes were observed. Cisternae of the Golgi complex were also more distended. Some acinar cells were in the process of lysis. Several vacuolar inclusions were present in some intralobular duct cells. Cellular material was seen in acinar and intralobular duct lumina. In these same regions, distended intralobular ducts and acinar lumina were observed. These last two features have never been reported in the reserpinized rat but are important manifestations of the pathology in cystic fibrosis patients where obstructions of ducts are believed to trigger focal destruction of the pancreatic tissue. These observations, along with the three parameters previously reported to be specifically altered by reserpine injections, clearly support the use of the chronically reserpinized rat as a reliable model for the study of cystic fibrosis. (Pediatr Res 25:482-489, 1989)
\end{abstract}

\section{Abbreviations}

CF, cystic fibrosis

RER, rough endoplasmic reticulum

GP-2, the major protein of the pancreatic zymogen granule membrane

Because of histologic, physiologic, and biochemical similarities existing between reserpine-treated animals and $\mathrm{CF}$ patients, the chronically reserpinized rat is the animal model of $\mathrm{CF}$ that has

Received July 11, 1988; accepted December 5, 1988.

Correspondence and reprint requests Dr. Denis LeBel, Department of Biology, University of Sherbrooke, Sherbrooke, QC, Canada, JIK 2RI.

Supported by a grant from the Canadian Cystic Fibrosis Foundation and NSERC to D.L. D.L. is a NSERC of Canada Research Associate.

1 This is the 10th paper in a series "Elucidation of the Mechanisms of Cellular Secretion." been the most studied (1-8). The main effects induced by the reserpine treatment on the ultrastructure of the pancreas are the following: an accumulation of granules in the acinar cell, an alteration of the granule ultrastructure, a slight diminution of the RER and Golgi apparatus, the presence of autophagic bodies, and an augmentation of lysosomal bodies $(3,5,9,10)$. In another paper (11), we report the effects of such a treatment on pancreatic growth and on the amount of a glycoprotein characteristic of the zymogen granule membrane, the GP-2. In this study, we specifically report the effects of chronic reserpine treatment at two doses, on the structure and ultrastructure of the rat pancreas. The effect of malnutrition, which is also induced by this treatment, was evaluated by including a group of pair-fed animals. The study is a thorough illustration, at the light and electron microscopic levels, of the transformations induced in the rat exocrine pancreas by chronic reserpine treatment.

\section{MATERIALS AND METHODS}

Four groups of five male Sprague-Dawley rats (200-275 g) were used in this study. The first two groups were injected daily intraperitoneally with reserpine at 0.5 or $1.0 \mathrm{mg} \cdot \mathrm{kg}^{-1}$ in a solution of benzyl alcohol, polyethylene glycol 300, and acetic acid (Martinez JR, personal communication). As discussed in another article (11), rats in the control group were injected with the vehicle used to dissolve the drug. The fourth group of rats was injected as the control group but received an amount of food equal to that ingested the day before by the group treated with reserpine at $0.5 \mathrm{mg} \cdot \mathrm{kg}^{-1}$. This constituted the group of pair-fed animals used to evaluate the effect of malnutrition induced by the treatment. All other animals received water and food (powdered rat food) ad libitum.

After $7 \mathrm{~d}$ of treatment, animals were fasted overnight before being killed by decapitation. Immediately after they were killed, three pieces of tissue were taken from different regions of the pancreas on each animal and fixed for 60 min in $2 \%$ glutaraldehyde buffered with Na cacodylate, $\mathrm{pH}$ 7.2. Tissue segments were postfixed for $60 \mathrm{~min}$ in $2 \%$ osmium tetroxide in the same buffer. Specimens were finally dehydrated and embedded in Epon 812 according to standard procedures. The remaining tissue was used for biochemical determinations as already reported (11).

For each piece of tissue, five $1-\mu \mathrm{m}$ thick sections were stained with toluidine blue for light microscopic examination. Micrographs were taken with a standard Universal Zeiss microscope equipped with an orange filter on Kodak 32 ASA Panatomic film. Electron microscopy was performed on thin, 70-nm thick sections stained with uranyl acetate and lead citrate. Observations were done on a Philips 201 electron microscope.

Although our objective in this study was not to conduct a morphometric evaluation, we were very concerned about the choice of plane of section to assess differences in size and quantity. We photographed what we considered representative areas that would allow comparisons of cells in similar orientation. 

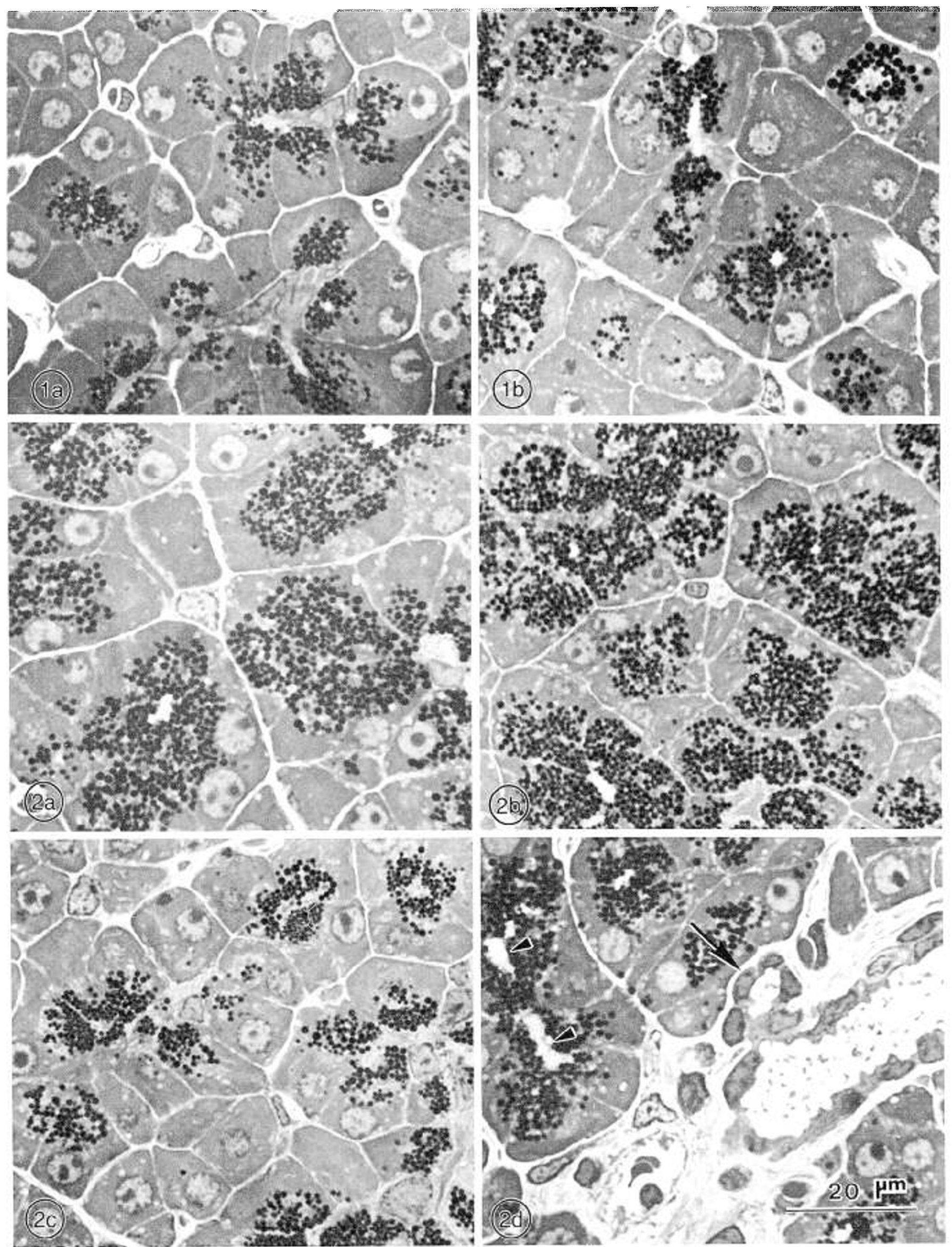

Fig. 1 and 2. Light microscopy of exocrine pancreatic tissue of control, reserpine-treated, and pair-fed rats (1325 $\times$ ). Pancreatic tissues of pair fed $(1 b)$ rats show no histologic differences with control $(1 a)$ rats. Granules occupy about one-third of the cell surface. In pancreas of rats treated during $7 \mathrm{~d}$ by daily intraperitoneal injection with $0.5(2 a)$ or $1.0(2 b) \mathrm{mg} \cdot \mathrm{kg}^{-1}$ of reserpine, granules are more numerous and occupy about two-thirds of the cell. Of treated animals, $40 \%$ show a normal number of granules $\left(2 c\right.$, at $\left.1.0 \mathrm{mg} \cdot \mathrm{kg}^{-1}\right)$. In all treated animals, some acinar lumina (arrowheads) and intralobular ducts (arrow) are distended $\left(2 d\right.$, at $\left.0.5 \mathrm{mg} \cdot \mathrm{kg}^{-1}\right)$. 
RESULTS

Light microscopy. The pancreatic tissue of pair-fed animals did not show any histological differences from sham-injected control animals. As shown in Figure 1, the structure of the exocrine pancreas was normal. The nucleus is located in the basal region, the RER is well developed, and zymogen granules occupy approximately one-third of the cell surface. The pancreas of animals treated with any of the two doses of reserpine had a very similar histology when compared to each other (Fig. $2 a$ and $b$ ). When compared to the control however, $60 \%$ of the treated rats showed more secretion granules occupying approximately two-thirds of the cell. The remaining $40 \%$ of the animals had an amount of granules in the pancreas similar to the sham-injected control (Fig. 2c). Dilated acinar and intralobular lumina were observed in certain regions of the pancreatic tissue in all treated animals (Fig. 2d). Detailed inspection of these areas revealed more particularly the presence of autophagic bodies in basolateral regions of acinar cells (Fig. $3 a$ ). These structures were also observed at the exterior of the cell (Fig. $3 b$ ). Cellular material was also found in intralobular ducts (Fig. 3c). Consistently observed in these particular regions bordering intralobular ducts were acinar cells in the process of lysis (Fig. $3 d$ and $e$ ). In intralobular ducts, some cells contained numerous vacuoles (Fig. $3 f)$.
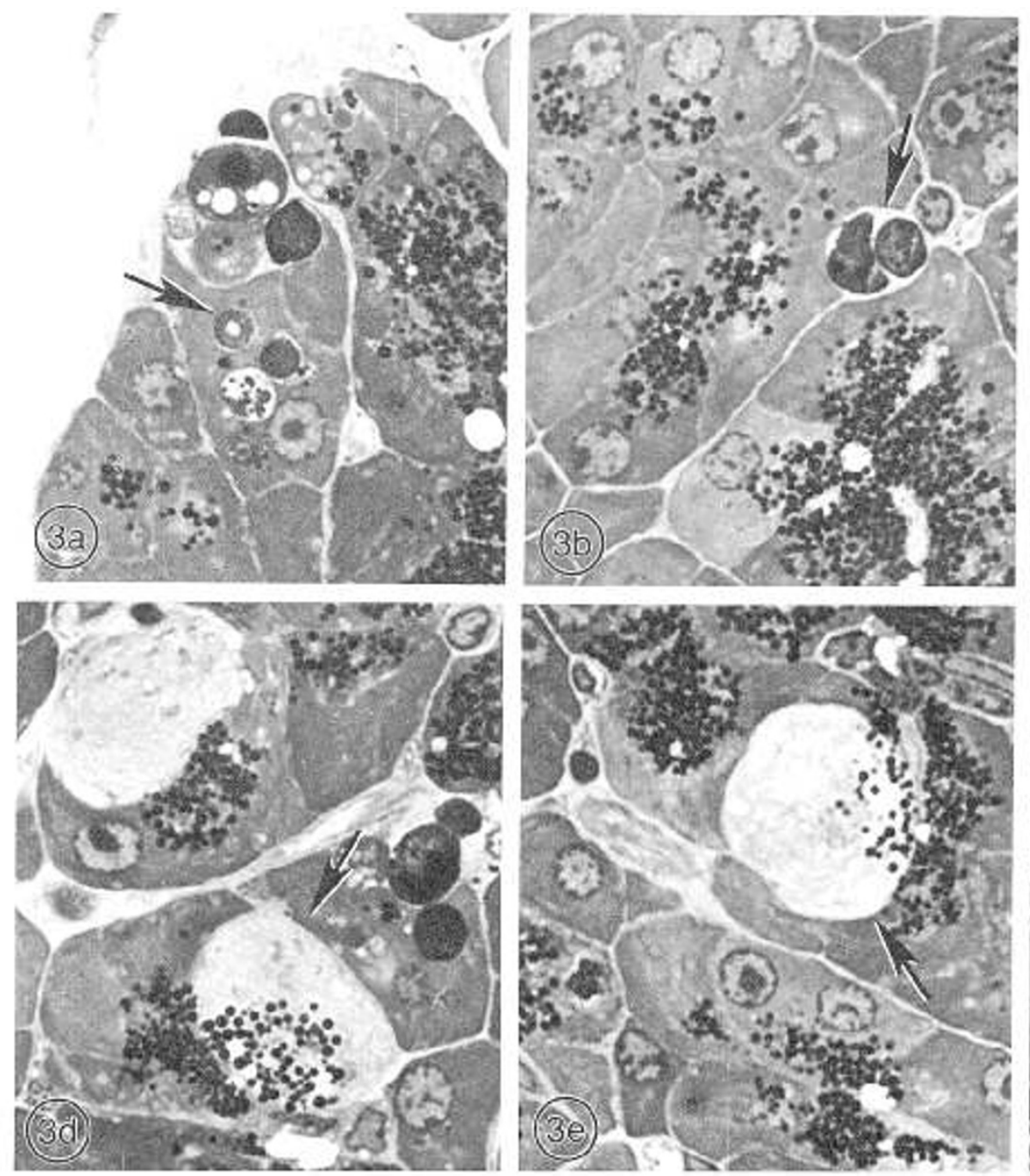

Electron microscopy. In general, observations done at the electron microscopic level confirmed in more details the observations made with the light microscope. The ultrastructure of the pancreatic exocrine cell of control and pair-fed animals were similar. An example of the ultrastructure of the pancreatic acinar cell of pair-fed animals is shown in Figure $4 a$. One can observe that the RER and the Golgi complex are well developed, that the granulation is uniform, and that acinar lumen contain many microvilli. By contrast, alterations in the acinar cell ultrastructure of all reserpinized animals were similar. No dose-dependent effects of the drug could be evaluated by such morphologic examination. As put in evidence with light microscopy, some regions of the gland of treated animals were normal and identical to controls except, as previously mentioned, for the amount of zymogen granules in some animals. Other regions of the tissue, however, displayed major alterations. The following descriptions of abnormalities are therefore restricted to regions of the pancreatic tissue affected by the treatment. As shown in Figure $4 b$, Golgi cisternae and acinar lumen are clearly dilated when compared to pair-fed tissue. The lumen appears expanded and contains few microvilli. Material present in these lumen are of a rather faint density to electrons. This swelling can be more accurately appreciated at higher magnification when compared to a normal acinar lumen (Fig. $4 c$ and $d$ ). The same phenomenon is observed more distally in some intralobular ducts (Fig. 5). Indeed, comparison of intralobular ducts from normal (Fig. 5b)

Fig. 3. Light microscopy of characteristic alterations of pancreatic tissue in reserpine treated rats (1325x). Autophagic bodies are present in the basolateral region of acinar cells ( $a$, in the cell) ( $b$, out of the cell). Cellular material is present in lumina of intralobular ducts ( $c$ ). Some acinar cells can be seen in the process of lysis $\left(d\right.$ and $e$ ). Some ductal cells are vacuolated $(f)$. The dose of reserpine was $0.5 \mathrm{mg} \cdot \mathrm{kg}^{-1}$. 

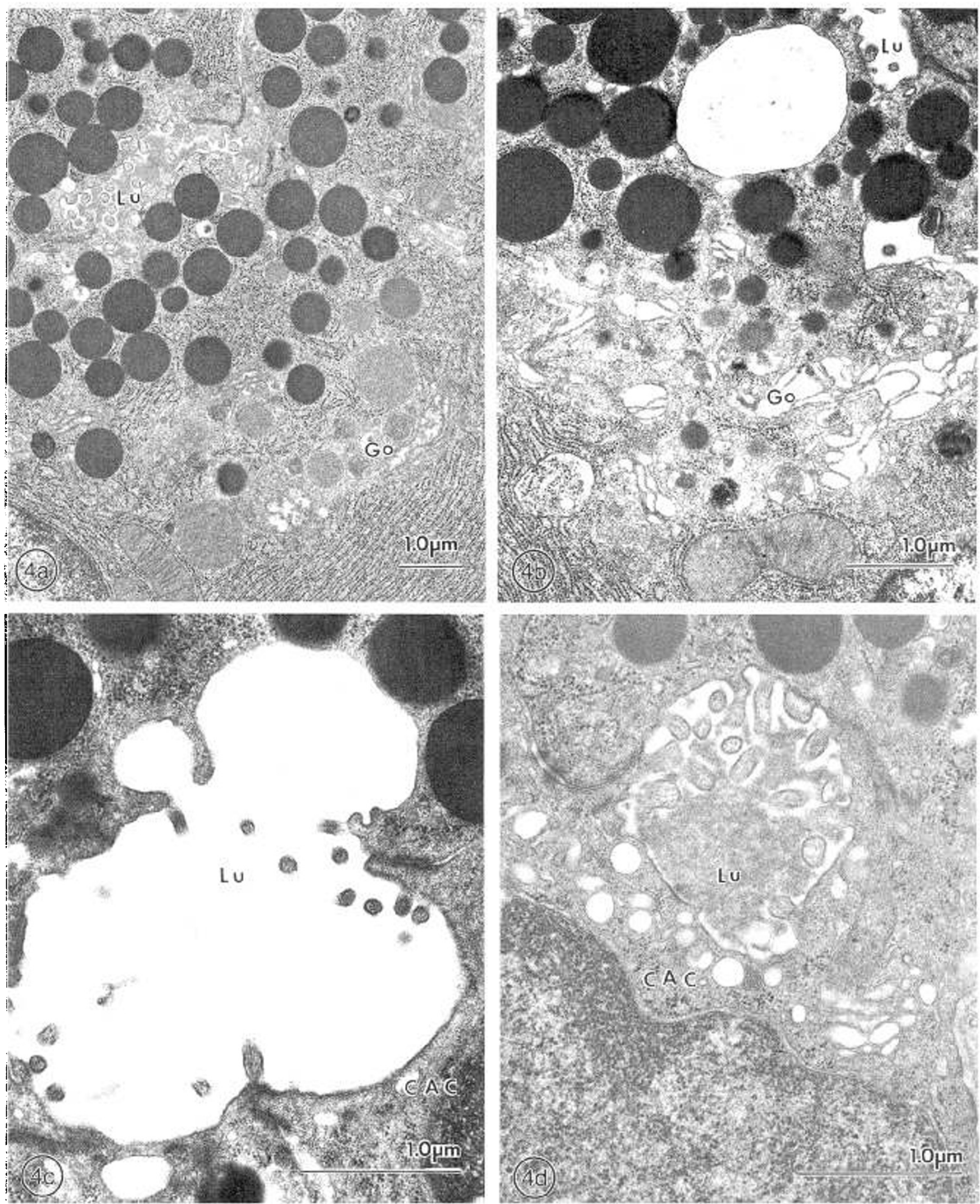

Fig. 4. Electron microscopy of exocrine pancreatic tissue of normal, pair-fed, and reserpinized rats. Pancreatic acinar cells of pair-fed rats $(a)$ shows no differences with control (not shown). Golgi is well developed, granules are normal, and acinar lumen contains secretory material as well as many microvilli $(11900 \times)$. In $b$, pancreatic acinar cells of reserpine-treated rats $\left(0.5 \mathrm{mg} \cdot \mathrm{kg}^{-1}, \mathrm{~d}^{-1}\right)$ show extensively dilated Golgi saccules and acinar lumen $(18500 \times)$. In $c$, high magnification of a dilated acinar lumen shows few microvilli and much less opaque secretory material as compared to control animals in $d .(29100 \times) L u$, lumen; $G o$, Golgi; $C A C$, centroacinar cell. 
and from treated tissues reveals obvious distension of the intralobular lumen in the reserpinized animals (Fig. 5a).

Another ultrastructural feature characteristic of the affected regions in the pancreatic tissue of treated rats is the presence of autophagic bodies. These vacuoles contain various cellular structures such as secretion granules, RER and nuclear material (Fig. $6 a$, and $b$ ). Amorphous and membrane-like materials were also found in these structures (Fig. $6 c$ and $d$ ). Figure $6 c$ shows an autophagic body in the apical region of the acinar cell, close to the lumen. Figure $6 d$ shows that fusion has taken place between an autophagic body containing myelin-like material and the apical membrane of the cell, releasing cellular debris in the acinar lumen. Such fusions would lead to the presence of different kinds of material in acinar lumina. Figure 7 is an illustration of the various materials that were observed. In Figure $7 a$, material very similar in density to secondary lysosomes can be seen. Cytoplasmic material (Fig. 7b), membrane sheets (Fig. 7c), or myelin figures (Fig. $7 d$ ) were also present in acinar lumina of treated rats. Table 1 summarizes our ultrastructural observations as well as those previously reported in the literature in the pancreas of reserpinized rats.

\section{DISCUSSION}

Chronic reserpine injection to rats induces a pathological state that mimics the general exocrinopathy observed in human $C F$

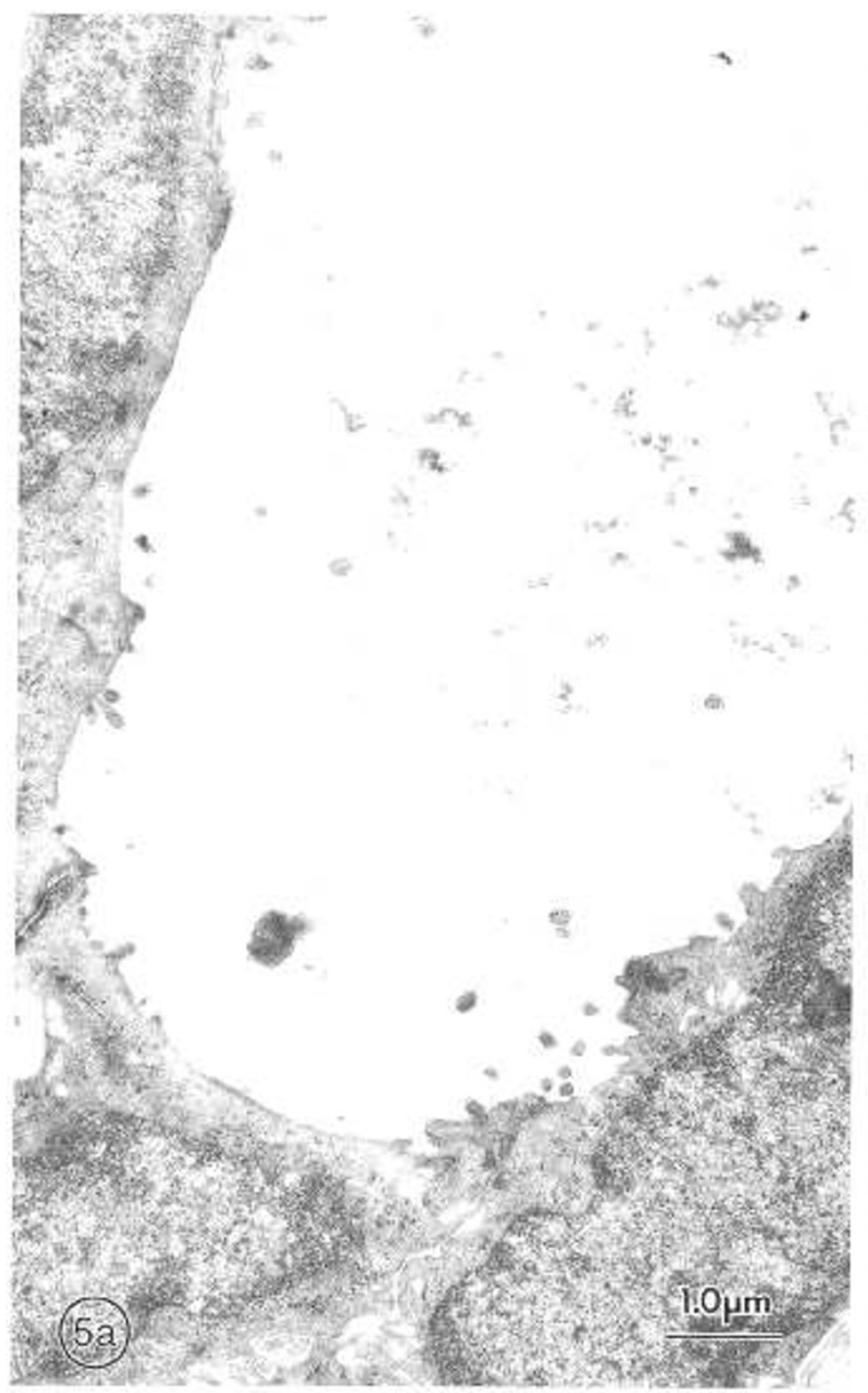

patients (1-8). The pancreas is severely affected by the disease leading to serious impairment of zymogen secretion by the gland (2-7). In a previous study (11), we assessed the effect of the reserpine treatment on the growth of the pancreas and on a particular protein of the secretory granule. In parallel, we have also carried out a thorough microscopic examination of the tissue in order to characterize the structural and ultrastructural alterations provoked in the unstimulated gland by the reserpine treatment. These observations are reported in the current study. Although not arising from a methodical morphometric study, these alterations led us to original and sound conclusions. All our observations have been compared to the most appropriate control, that is, pair-fed animals $(11,12)$.

Using biochemical and secretion studies, Hazlett et al. (12) have been the first to raise the importance of including pair-fed animals in studies involving chronic reserpine treatment. This report is the first one where a thorough morphological examination is carried out on the pancreas of such pair fed animals. No noticeable differences were found between pancreases of control and those of pair-fed rats. As this is the first study with pair-fed rats in such experimental conditions, the only comparison that can be done is with fasted animals. It has been reported before that very severe starvation did not induce pronounced morphologic alterations of the pancreatic acinar cell morphology (13). In this study, food restriction was only partial for pair-fed animals. That no major effects were observed on the morphology

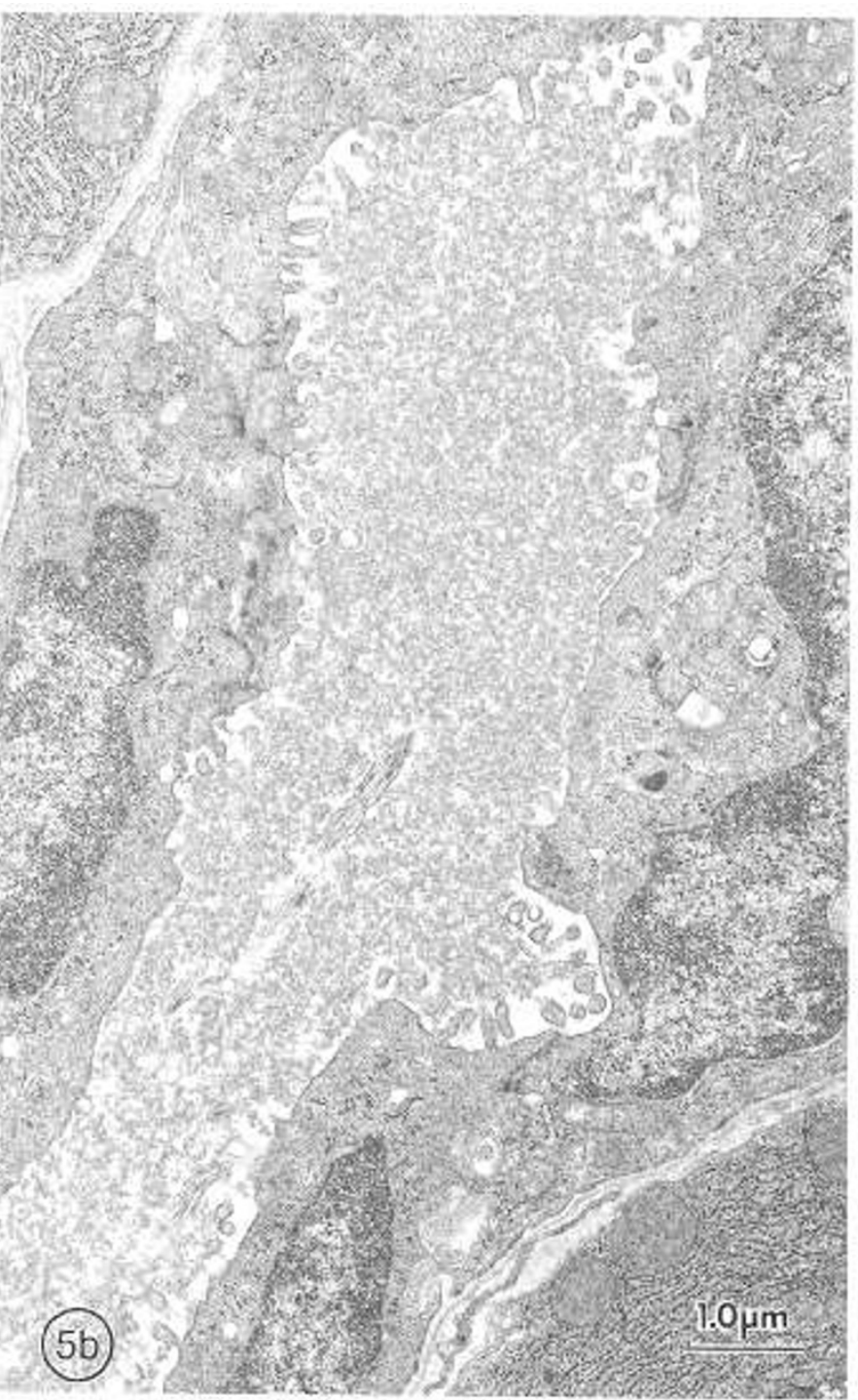

Fig. 5. Pancreatic intralobular ducts of control and reserpinized rats. Electron microscopy. In $a$, pancreas of reserpine-treated rats $\left(0.5 \mathrm{mg} \cdot \mathrm{kg}^{-1}\right.$, $\mathrm{d}^{-1}$ ) show dilated intralobular ducts. By comparison in $b$, intralobular ducts of control animals contain relatively dense material, microvilli, and do not present any distention $(11900 \times)$. 

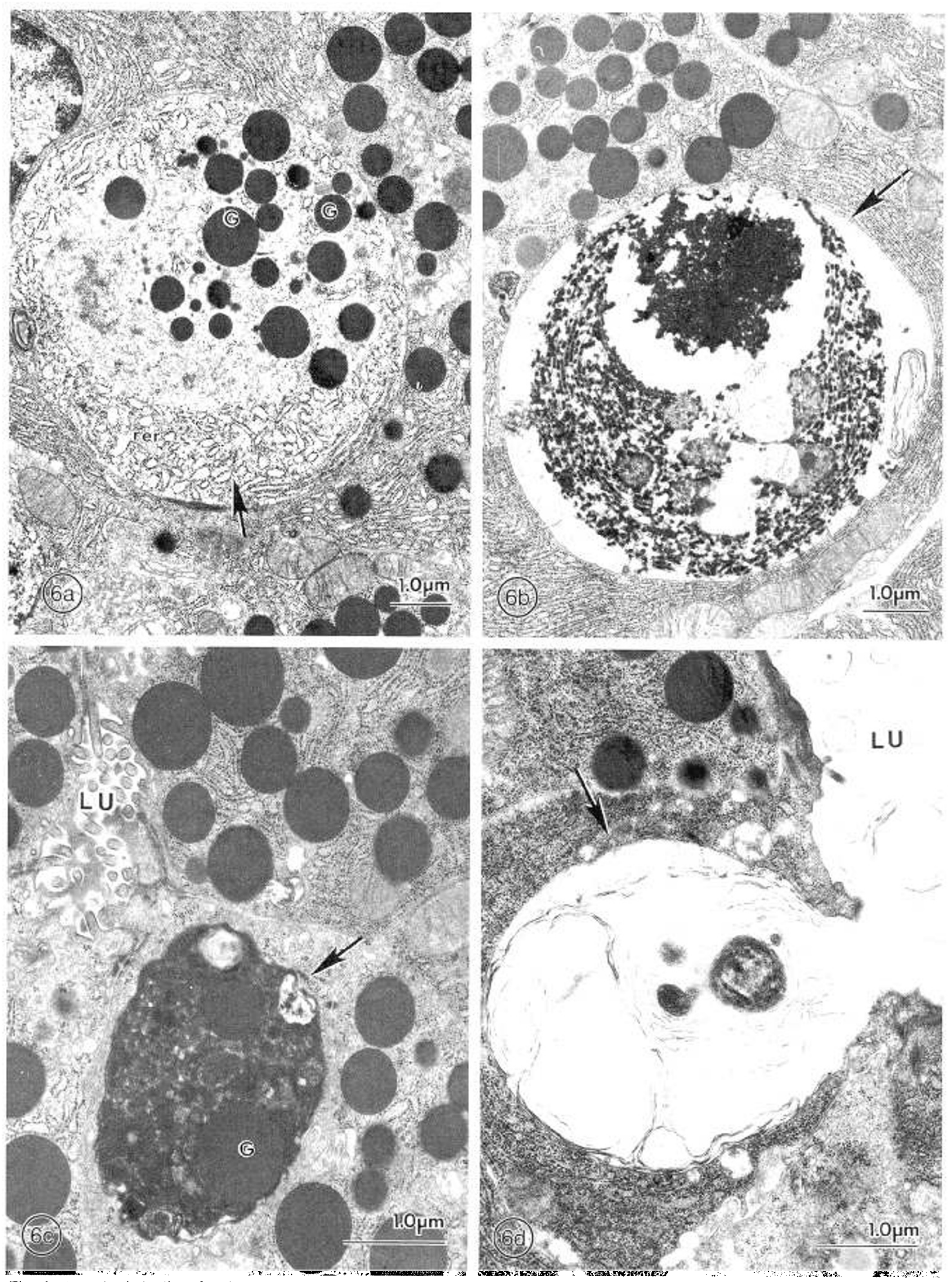

Fig. 6. Autophagic bodies of various content observed in the pancreas of reserpinized rats. Electron microscopy. Pancreas of reserpine-treated rats $\left(0.5 \mathrm{mg} \cdot \mathrm{kg}^{-1}, \mathrm{~d}^{-1}\right)$. In $a$, an autophagic body contains zymogen granules and RER (arrow); in $b$, nuclear material; in $c$, zymogen granules and amorphous material; in $d$, an autophagic body has discharged its membranous content in the acinar lumen ( $a$ and $b, 11900 \times ; c$ and $d, 18500 \times$ ). $G$, zymogen granule; $L u$, lumen. 

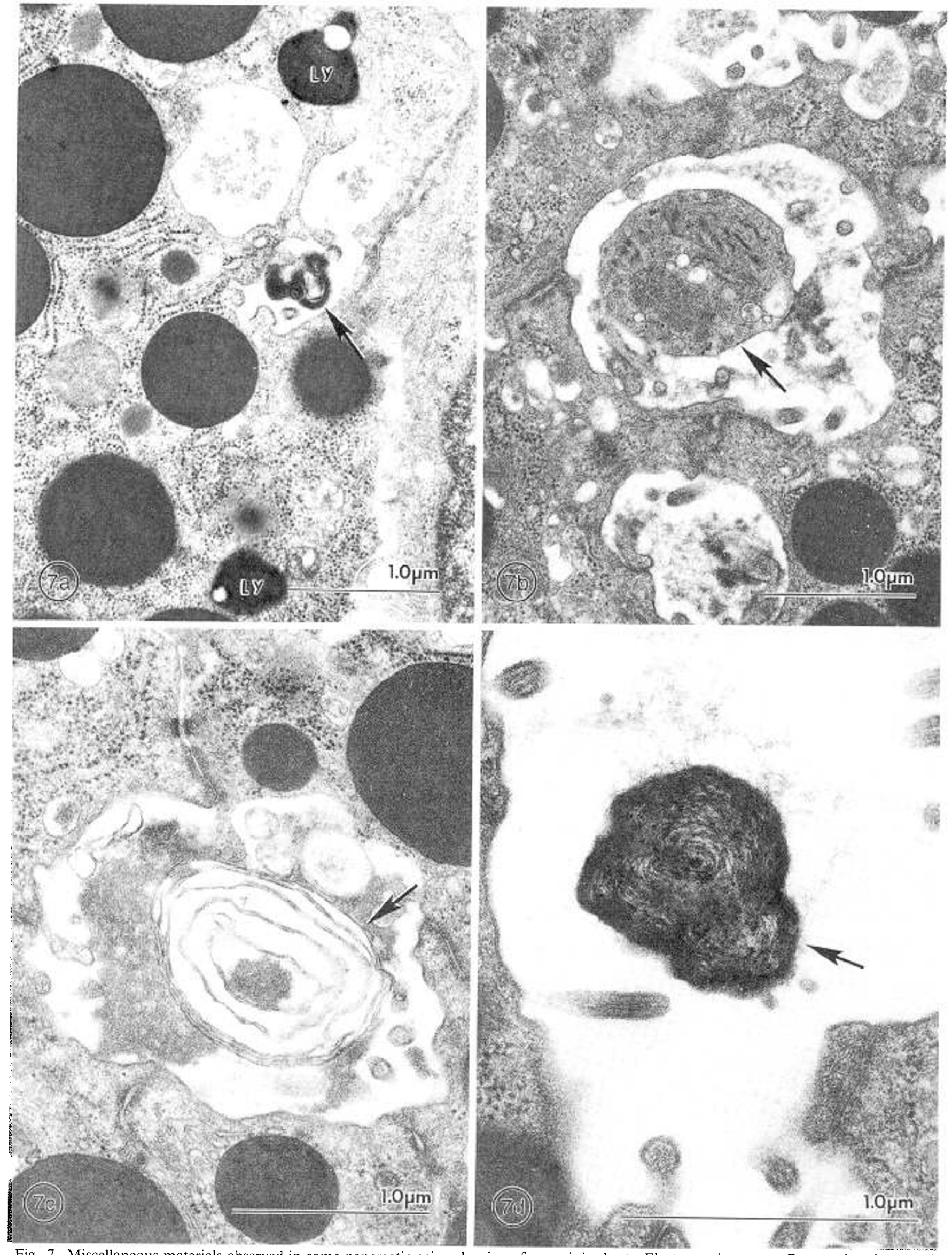

Fig. 7. Miscellaneous materials observed in some pancreatic acinar lumina of reserpinized rats. Electron microscopy. Pancreatic acinar lumina of reserpine-treated rats $\left(0.5 \mathrm{mg} \cdot \mathrm{kg}^{-1}, \mathrm{~d}^{-1}\right.$ in $a, b, d$, and $1.0 \mathrm{mg} \cdot \mathrm{kg}^{-1}, \mathrm{~d}^{-1}$ in $c$ ) contain various material (arrows); in $a$, lysosome-like material; in $b$, cytoplasmic material; in $c$, membranous material; in $d$, a myelin figure $(a$ and $b, 29100 \times ; c, 37600 \times ; d, 56800 \times)$. $L y$, lysosome. 
Table 1. Ultrastructural alterations in the exocrine pancreatic tissue of chronically reserpinized rats

\begin{tabular}{ll}
\hline \multicolumn{1}{c}{ Previously observed (Ref.) } & \multicolumn{1}{c}{ This study } \\
\hline Massive increase in the number of secretion granules $(3)$ & Accumulation of secretion granules in \\
Variations of density and diameter of zymogen granules $(3,5,9)$ & $60 \%$ of treated animals \\
& Normal density and diameter of se- \\
cretion granules & RER area varies in inverse proportion \\
Slight reduction of RER $(3,9)$ & with amount of granules \\
Golgi reduced in vol and in number of constituting cisternae (3) & Distended Golgi cisternae \\
Numerous autophagic bodies $(3,10)$ & Same observation \\
Increased number of lysosomes $(3,9)$ & Same observation \\
Vacuolar inclusions in intralobular duct cells $(3)$ & Same observation \\
Not mentioned & Small ducts obstructed with debris \\
& from acinar cells* \\
Not mentioned & Distension of ducts in some regions \\
& of the tissue* \\
\hline
\end{tabular}

* Observations reported in human tissue $(14,15,16)$.

of the tissue is therefore not surprising. Regarding the treated animals, however, about $60 \%$ of them had more granules in their pancreas. Such an accumulation of secretory granules in the pancreas of treated rats has previously been reported (3). Simultaneously with the accumulation of granules, we have also observed in these same specimens that the apparent area occupied by the RER was smaller. These observations have also been previously reported by Setser et al. (3). In addition, they have observed in situ using a fasting period of $24 \mathrm{~h}$, that granules varied considerably in size, and in some cells, occasional granules were bizonal. We did not observe such a phenomenon, but similar granules can be found in very limited amounts in normal tissue. In addition, fasting alone can induce the formation of bizonal granules (13). It is therefore possible that the much longer fasting period used by Setser et al. $(24 \mathrm{~h}$, instead of $12 \mathrm{~h}$ in our case) could be the sole explanation for the difference on this point. At first glance, the morphologic observations reported here on the accumulation of zymogen granules seems to contradict the significant decrease in the content of amylase in the pancreas of treated animals as reported in a companion paper (11) and also by other groups $(7,12)$. While amylase activity decreased, chymotrypsinogen and lipase activities were very significantly increased. These latter zymogens are, among other zymogens that have not been tested, responsible for filling the increased number of granules observed. Therefore amylase should be used with prudence as the sole indicator of the quantity of granules in the pancreatic tissue under given experimental conditions that could affect the ratio of zymogens in the gland of, as for example here, the reserpinized rat.

Finally, although some regions of the pancreatic tissue of treated animals had a normal aspect, other regions were strongly affected by the treatment. These ultrastructural observations were consistent in all treated animals and were depicted by the presence of autophagic bodies and lysosomes in acinar cells as well as several vacuolar inclusions in some intralobular duct cells. In addition, cellular material was seen in acinar and intralobular duct lumina. In the same regions, distended intralobular ducts and acinar lumina were also noticed. These expanded lumina are believed to be upstream of ducts obstructed by the cellular debris mentioned above. These two last features have never been reported in the reserpinized rat model of $\mathrm{CF}$, but are important manifestations of the pathology in CF patients $(14,15)$. Indeed, in the human, obstructions caused by precipitated secretions and cellular debris are believed to lead to acinar disruption, autodigestion of acini, and replacement by cysts of fibrous tissue in the region of the pancreas drained by obstructed ducts (14-16). Pancreatic duct obstructions reported here in the rat model of $\mathrm{CF}$ are comparable to observations in the human situation where such obstructions are thought to trigger, in the pancreas, symptoms of pathology. If reserpine injections could be prolonged, it is conceivable that the pancreas of treated rats could look like those of $\mathrm{CF}$ patients. In additon to three pancreatic parameters previously reported as specifically affected by reserpine (i.e. pancreatic wt, lipase, and GP-2 contents) (11), the ultrastructural alterations reported here would validate the chronically reserpinized rat as a reliable model for the study of the human pathology of CF.

Acknowledgments. The authors acknowledge the excellent technical assistance of Marlyne Beattie and Micheline Vanier. Thanks to Dr. Brian Talbot for very helpful comments.

\section{REFERENCES}

1. Martinez JR, Adelstein E, Quissel D, Barbero GJ 1975 The chronically reserpinized rat as a possible model for cystic fibrosis. Pediatr Res 9:463469

2. Perlmutter J, Martinez JR 1978 The chronically reserpinized rat as a model for cystic fibrosis. VII. Alterations in the secretory response to cholecystokinin and to secretin from the pancreas in vivo. Pediatr Res. 12:188-194

3. Setser ME, Spicer SS, Simson JAV, Adamson M, Martinez JR 1979 The effects of reserpine on the ultrastructure and secretory responses of rat exocrine pancreas. Exp Mol Pathol 31:413-422

4. Morton D, Parker D, Estrada P, Martinez JR 1980 Exocrine pancreatic secretion in rats treated with reserpine after stimulation with pilocarpine, dopamine, caerulein. Pediatr Res 14:18-20

5. McCurdy RE, Martinez JR 1981 The chronically reserpinized rat as a model for cystic fibrosis: alterations in pancreatic enzyme secretion and storage. Pediatr Res 15:1308-1313

6. Roomans GM, Wei X, Ceder O, Kollberg H 1982 The reserpinized rat in the study of cystic fibrosis: $x$-ray microanalysis of submandibular gland and pancreas. Ultrastruct Pathol 3:285-293

7. Joehl RJ, DeJoseph MR 1985 Pancreatic enzyme secretion in experimental cystic fibrosis. In: Martinez JR, Barbero GJ (eds) Animal Models for Cystic Fibrosis: The Reserpine-Treated Rat. San Francisco Press, San Francisco, pp $119-124$

8. Spicer SS, Simson JAV, Martinez JR 1985 Cytochemical and ultrastructural alterations induced by reserpine in exocrine glands. In: Martinez JR, Barbero GJ (eds) Animal Models for Cystic Fibrosis: The Reserpine-treated Rat. San Francisco Press, San Francisco, pp 13-21

9. Barbero GJ 1985 A clinician looks at an animal model for cystic fibrosis. In: Martinez JR, Barbero GJ (eds) Animal Models for Cystic Fibrosis: The Reserpine-treated Rat. San Francisco Press, San Francisco, pp 165-172

10. Werlin SL, Harb JM, Stefaniak J, Taylor T 1985 Pancreatic structure and function in the immature reserpinized rat. Exp Molec Pathol 39:24-36

11. Leblond FA, Morisset J, LeBel D 1989 Alterations of pancreatic growth and of GP-2 content in the reserpinized rat model of cystic fibrosis. Pediatr Res $25: 478-481$

12. Hazlett D, Korc M, Brannon PM 1986 Effects of malnutrition and chronic reserpine treatment on pancreatic exocrine function. Pediatr Res 20:12361239

13. Bendayan M, Bruneau A, Morisset J 1985 Morphometrical and immunocy. tochemical studies on rat pancreatic acinar cells under control and experimental conditions. Biol Cell 54:227-234

14. Oppenheimer EH, Esterly JR 1975 Pathology of cystic fibrosis: review of the literature and comparison with one hundred and forty-six autopsied cases. Perspect Pediatr Pathol 2:241-278

15. Lebenthal E, Lerner A, Heitlinger L 1986 The pancreas in cystic fibrosis. In: Go VLW (eds) The Exocrine Pancreas: Biology, Pathobiology and Diseases. Raven Press, New York, pp 783-817

16. Kopito LE, Shwachman H, Vawter GF, Edlow J 1976 The pancreas in cystic fibrosis: chemical composition and comparative morphology. Pediatr Res 10:742-749 